\title{
Partial aortic cross-clamping, inflammation and oxidative stress response: Does anaesthetic matters?
}

\author{
Morillas-Sendín P, Barranco M, Ruiz M, Soroa M, Poveda D, Quintana-Villamandos B. \\ Gregorio Marañón University General Hospital, Dept of Anaesthesiology \& Intensive Care, Madrid, Spain.
}

Background and Goal of Study

Inflammation and oxidative stress are considered as key mediators of complications after cardiac surgery. Sevoflurane, compared with propofol-based anesthesia, attenuated the release of serum markers of cellular injury in a model of thoracic-aortic occlusion in pigs $(\mathrm{I})$ and provided greater protection against myocardial oxidative stress in off-pump coronary surgery (2).

This study has been performed on the hypothesis that sevoflurane-based anesthesia reduces inflammation and oxidative stress compared with propofol-based anesthesia during partial aortic clamping.

\section{Materials and methods}

Ten healthy minipigs were divided into 2 groups $(5$ per group) according to the anaesthetic received (sevoflurane $2 \%$ or propofol II-I $\mathrm{mg} / \mathrm{kg} / \mathrm{h})$.

After median sternotomy, a side clamp (20min) was applied in the ascending aorta (Fig I).

To investigate the inflammatory and oxidative stress response to partial aortic clamping we studied the biomarkers: Heat shock protein 70 (Hsp70), C3a, tumor necrosis factor (TNF) and nitric oxide at baseline (before aortic cross-clamp) and after aortic crossclamp removal (reperfusion). Arterial blood samples were analyzed. All data were expressed as mean \pm SEM.

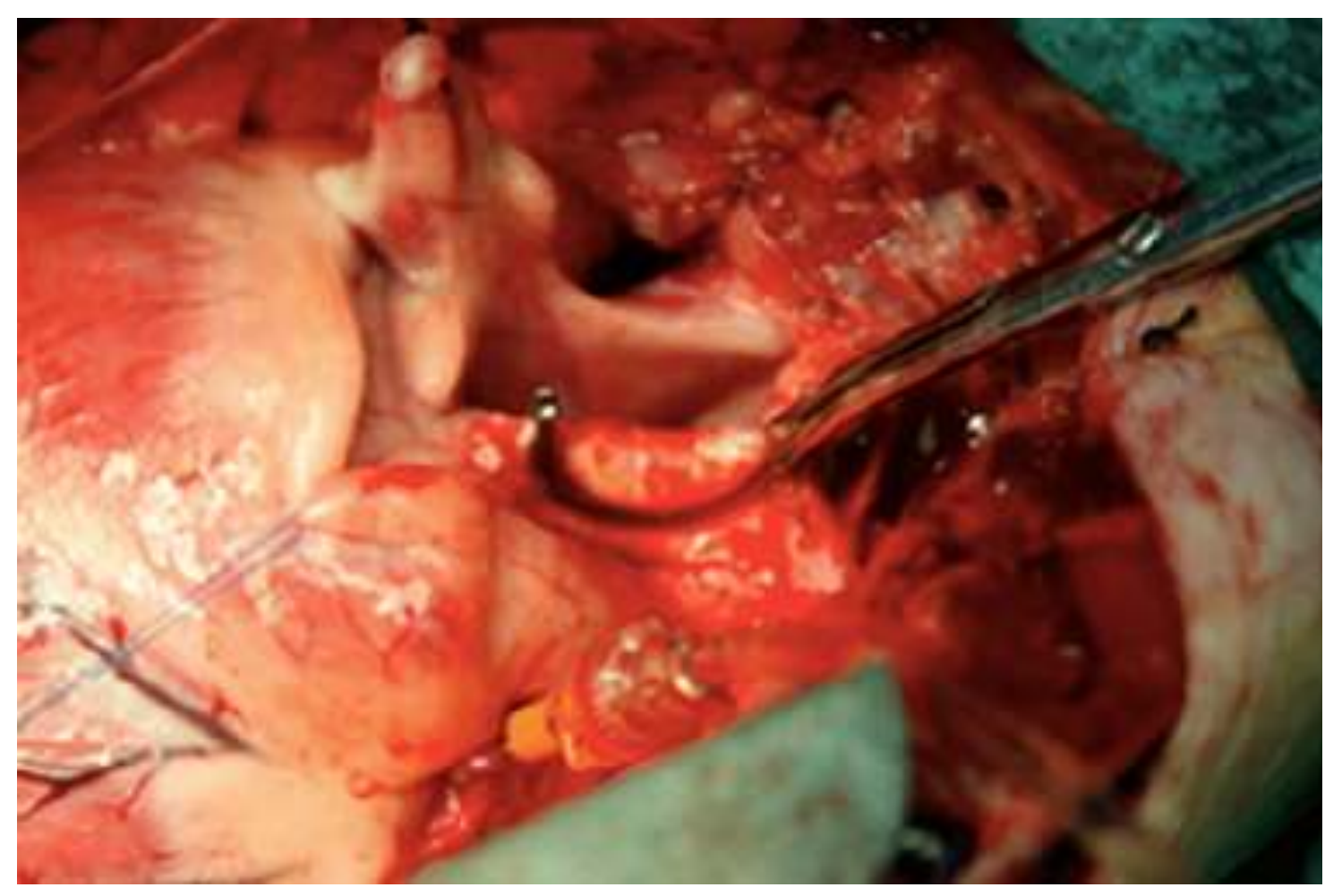

Fig. I: Side clamp in the ascending aorta.

\section{References}

I. Annecke T, Kubitz JC, Kahr S, et al. Effects of sevoflurane and propofol on ischaemia-reperfusion injury after thoracic-aortic occlusion in pigs. $\mathrm{Br} J$ Anaesth. 2007;98:581-90.

2. Ballester M, Llorens J, Garcia-de-la-Asuncion J, et al. Myocardial oxidative stress protection by sevoflurane vs propofol: a randomised controlled study in patients undergoing off-pump coronary artery bypass graft surgery. Eur J Anaesthesiol 2011;28:874-8I.

3. Erturk E. Ischemia-Reperfusion Injury and Volatile Anesthetics. BioMed Research International. 2014, Article ID 52630I, 7 pages.

4. Manohar M, Parks CM. Porcine systemic and regional organ blood flow during 1,0 and 1,5 minimum alveolar concentrations of sevoflurane anesthesia without and with 50\% nitrous oxide. J Pharmacol Exp Ther. 1981;23:640-8.

5. Mathur S, Farhangkhgoee P, Karmazyn M. Cardioprotective effects of propofol and sevoflurane in ischemic and reperfused rat hearts: role of K(ATP) channels and interaction with the sodium-hydrogen exchange inhibitor HOE 642 (cariporide). Anesthesiology. 1999; 91:1349-60.

\section{Results}

Animals in both intervention groups did not differ in terms of sex (male/female 5/0) and body weight (sevoflurane $34 \pm \mathrm{l} \mathrm{kg}$; propofoll $25 \pm 3 \mathrm{~kg}$ ).

At baseline, comparable values were obtained in both groups. The results showed that, after aortic cross-clamp removal, there was no significant difference between the two groups, sevoflurane and propofol (Table I).

\begin{tabular}{|c|c|c|c|}
\hline & $\begin{array}{c}\text { PROPOFOL } \\
(n=5)\end{array}$ & $\begin{array}{l}\text { SEVOFLURANE } \\
(n=5)\end{array}$ & p \\
\hline \multicolumn{4}{|l|}{ Hsp70 } \\
\hline Baseline & $5.12 \pm 1.11$ & $4.08 \pm 0.27$ & 0.386 \\
\hline After PAC & $5.68 \pm 1.49$ & $4.55 \pm 0.48$ & 0.489 \\
\hline \multicolumn{4}{|l|}{ C3a } \\
\hline Baseline & $22.35 \pm 4.75$ & $13.11 \pm 4.10$ & 0.191 \\
\hline After PAC & $18.92 \pm 3.29$ & $13.26 \pm 3.77$ & 0.301 \\
\hline \multicolumn{4}{|l|}{ TNF } \\
\hline Baseline & $42.70 \pm 8.24$ & $33.56 \pm 16.70$ & 0.615 \\
\hline After PAC & $29.16 \pm 0.92$ & $34.68 \pm 10.68$ & 0.566 \\
\hline \multicolumn{4}{|l|}{ Nitric Oxide } \\
\hline Baseline & $610.06 \pm 33.96$ & $732.61 \pm 129.93$ & 0.514 \\
\hline After PAC & $418.12 \pm 66.44$ & $691.27 \pm 11.81$ & 0.143 \\
\hline
\end{tabular}

\section{Discussion}

The results showed not statistically significant difference neither in inflammatory response nor in nitric oxide between sevoflurane and propofol groups at baseline and after removal of partial clamping of ascending aorta. Sevoflurane, compared with propofol, attenuated the haemodynamic sequelae of reperfusion injury and release of serum markers of cellular injury in a model of thoracicaortic occlusion in pigs ( $\mathrm{I})$.

Oxidative stress and reperfusion injury may develop after ischemia-reperfusion injury (IRI). The main organs in which IRI occurs are heart, lung, brain, liver, kidney, and intestine (3). Nevertheless, in our study, we did not use cardiopulmonary bypass, so there was no ischemia/reperfusion injury.

\section{Study Limitations}

The effects of inhaled anesthetics (4) and the intravenous anesthesia (propofol, opioids) (5) may be dose-dependent. The concentration of sevoflurane we used represents approximately I minimum alveolar concentration, which is similar to the concentration used in other studies that show beneficial effects in a model of ischemia-reperfusion after thoracic-aortic occlusion in pigs (I).

\section{Conclusions}

After ascending aorta partial clamping, sevoflurane-based anesthesia did not reduce inflammation and oxidative stress compared with propofol-based anesthesia. 